\title{
Reprodução das Elites, Consumo e Organização do Espaço Urbano: Questões Comparativas entre a Barra da Tijuca e a Zona Sul do Rio de Janeiro
}

\author{
Luiz Henrique Lemos*
}

\section{Resumo}

Este artigo pretende levantar hipóteses que possam explicar as diferenças de valores, gostos, formas de consumo e 0 sentimento de diferença do segmento da elite estabelecido fundamentalmente na Zona Sul do Rio de Janeiro em relação aos grupos economicamente emergentes estabelecidos, em sua grande maioria, na Barra da Tijuca. Este estudo é o primeiro esforço em busca de respostas de questões que surgiram em função da dissertação de mestrado deste autor. Foi através dela que se identificou a existência de um forte sentimento de identidade e diferença entre os grupos sociais que serão aqui citados: os detentores do capital simbólico e os economicamente emergentes.

Palavras-chave: capital simbólico ; grupos economicamente emergentes; habitus.

\begin{abstract}
This paper aims hypotheses that can explain the differences of values, taste, consumption forms and considerable segregation feelings from the elite segments established fundamentally in the Rio de Janeiro south area in relation to the emerging economically groups established, in their great majority, in Barra da Tijuca. This work is the first effort to answers some questions that appeared in this author's master's degree dissertation. It was through that identified the existence of a strong identity feeling and difference among the social groups that will be mentioned here: the symbolic capital holders and the economically emerging groups.
\end{abstract}

Keywords: symbolic capital; economically emerging groups; habitus.

\section{Introdução}

A cidade, como forma de organização espacial humana, é mais do que reflexo da sociedade; é, antes de tudo, sua própria estruturação social, reproduzida num espaço relativamente limitado. Para Oliven (1996), as cidades constituem os centros mais dinâmicos de sociedades complexas; e representam também espaços nos quais as contradições desse tipo de sociedade se tornam mais evidentes.

A forma como a sociedade organiza o processo de produção determina a divisão social do trabalho, que por sua vez atribui aos lugares determinada forma de ocupação e identidade. Isso quer dizer que há espaços geográficos "próprios" para cada grupo social ou fração deste, de acordo com a posição ocupada no sistema de produção. A cidade é, portanto, o local onde a luta pelo espaço é regida pela mesma luta histórica dinamizada pelas diferenças entre os grupos sociais, decorrentes da organização da produção.

No caso brasileiro, Oliveira (1982) destaca como uma economia fundada na escravidão, na monocultura e na utilização do litoral como meio de escoamento de produtos primários influenciou na divisão social do trabalho. As cidades, por serem centro das atividades comerciais e terem atraído mão-de-obra pouco qualificada, tornaram-se razão de um crescimento concentrado.

As desigualdades decorrentes da organização da produção surgem em todas as sociedades capitalistas. Essa condição comum aparece com mais contraste em sociedades onde a distribuição de renda é mais desigual. $\mathrm{O}$

\footnotetext{
* Coordenador e professor da Universidade Cândido Mendes. Doutorando em planejamento urbano pelo IPPUR/UFRJ. Mestre em administração pela EBAPE/FGV e especialista em Tecnologia de Geoprocessamento pela CEGEOP - UFRJ e em marketing pela PUC-RJ. E-mail: Ihlemos@ candidomendes.edu.br.

Artigo recebido em junho de 2004 e aceito em julho de 2004.
} 
Brasil é hoje uma das sociedades com a mais injusta distribuição de renda do mundo, o que torna o país bastante emblemático quando se estuda um tema relacionado à configuração das hierarquias sociais.

A tendência à dualização da estrutura social propicia a apropriação cada vez mais exclusiva dos espaços mais valorizados pelas funções ligadas ao consumo e à moradia de luxo e, por outro lado, a conformação de espaços exclusivos da pobreza (LAGO, 2000).

A noção de exclusão social ou nova pobreza está relacionada à esfera do trabalho e à esfera da sociabilidade. Por um lado, a reestruturação produtiva e a conseqüente retração dos empregos teriam instituído uma nova divisão social do trabalho, marcada não mais pela inserção diferenciada dos trabalhadores e sim pelos inseridos e pelos não inseridos no sistema produtivo hegemônico (LAGO, 2000, p.25).

No Rio de Janeiro, a segregação urbana demonstrou ser ainda mais crítica do que em outras grandes metrópoles brasileiras. Após o término da monarquia, no final do século XIX, fatores históricos e políticos contribuíram para uma crescente segregação socioespacial, sem falar nas características geomorfológicas da cidade que dificultaram a sua expansão, o que contribuiu para a polarização da estrutura espacial, acentuando os vínculos entre localização e posição social.

Para melhor compreensão da estruturação espacial da cidade, é necessário buscar na história os fatos que definiram a sua atual configuração social: o governo municipal do Rio de Janeiro do início do século XX tornou-se o principal ator na consolidação da segregação urbana. Na gestão do então prefeito Pereira Passos pretendia-se, através de ampla intervenção urbana, reestruturar a cidade com o objetivo de tornar a capital brasileira da época, um local comercial e socialmente à altura das grandes metrópoles européias.

A reforma urbana de Pereira Passos visava, sobretudo resolver as contradições que ela apresentava. Era imperativo agilizar todo o processo de importação/exportação de mercadorias, que ainda apresentava características coloniais devido à ausência de um moderno porto. Era preciso, também, criar uma nova capital, um espaço que simbolizasse concretamente a importância do país como principal produtor de café do mundo, que expressasse os valores e o modus vivendi cosmopolita e moderno das elites econômica e política nacionais. Nesse sentido, deu-se o rápido crescimento da cidade em direção à Zona Sul (ABREU,1997, p.60).

A evolução da cidade do Rio de Janeiro no início do século XX espelhava exatamente as contradições existentes no sistema político-econômico do país naquela época. $\mathrm{O}$ governo federal e municipal representavam os interesses das classes dominantes, envolvidas na revitalização do Centro e no embelezamento da Zona Sul.

Morar na Zona Sul transformou-se em símbolo de status. A indústria imobiliária, estimulada pela demanda e pela falta de leis de zoneamento e ocupação, construiu freneticamente novos edifícios. A explosão imobiliária aconteceu, com mais força, nas décadas de 1940 e 1950 (FRAIHA, 2000).

Na tentativa de ordenar tal crescimento e ocupação, surgiu o plano, durante o mandato do então Prefeito Prado Júnior, sob orientação de Alfred Agache, cujo primeiro intento importante foi o de buscar ordenar o processo de crescimento da cidade, a partir de critérios urbanísticos aceitáveis dentro da visão da classe dominante. $\mathrm{O}$ Plano Agache pretendia transformar o Rio de Janeiro (ou pelo menos o Centro e a Zona Sul) numa cidade monumental (ABREU, 1997, p.86).

Com pouco apoio do governo, as indústrias proliferam em direção aos subúrbios, onde os terrenos eram abundantes e pouco valorizados. Centro e Zona Sul, de um lado, e subúrbios, de outro, passam a ser impulsionados por forças divergentes que aumentavam ainda mais a polarização que caracteriza a ocupação do solo carioca. Os subúrbios atraíam cada vez mais trabalhadores em busca de oportunidades nas indústrias que ali se estabeleceram. Em contrapartida, em função da ocupação da Zona Sul pela elite, houve uma súbita valorização do solo na região, o que define o seu destino como área fundamentalmente residencial, principalmente da elite, mantendo-se dessa forma até hoje (ABREU, 1997).

Há um uso privilegiado do território em função das forças hegemônicas. Estas, por meio de suas ordens, comandam verticalmente o território e a vida social, relegando o Estado a uma posição de coadjuvante ou de 
testemunha, sempre que ele se retira, como no caso brasileiro, do processo de ordenação do uso do território (SANTOS, 2000, p.23).

A partir de 1964, a burguesia financeira deixa o seu papel de mero colaborador da burguesia industrial para assumir também um lugar dominante na economia. Nesse período, correspondente aos primeiros anos do regime militar, intensificava-se a retirada da população de baixa renda da Zona Sul (ABREU, 1997), quando as favelas foram praticamente extintas na região (ABREU, 1997). Por outro lado, a "permissão vigiada" desse tipo de habitação garantia uma mão de obra barata a serviço das classes dominantes. Assim, as favelas da Zona Sul eram (de alguma forma ainda são), a "área de serviço" da elite carioca. Entretanto, nos últimos 20 anos a elite, representada nos governos estadual e municipal, vem perdendo o controle da expansão das favelas, não só na Zona Norte e Oeste, como também na própria Zona Sul, apesar do número de favelas a partir de meados dos anos 1960 ter praticamente crescido apenas na Zona Norte. Durante as décadas de 1980 e 1990, houve crescimento do número de habitantes em todas as favelas cariocas. Esse crescimento permanece até hoje muito superior ao restante da cidade.

A política de remoção de favelas implementada nesse período veio complementar um conjunto de ações públicas e privadas voltadas para a sobrevalorização dessas áreas. Cerca de 175 mil pessoas haviam sido removidas até 1968, mas só a partir desse ano, até 1973, o programa foi mais sistemático e intenso. Convém mencionar o caráter seletivo dessa política, na medida em que $70 \%$ dos domicílios removidos localizavam-se na Zona Sul, Tijuca e Méier. O resultado foi a perda de representatividade das favelas da Zona Sul: se, em 1950, 25,4\% da população favelada estavam na Zona Sul, em 1970, apenas 9,6\% ainda residiam na área (CASTRO apud LAGO, 2000, p.75).

A partir da década de 1960, a parte final da Zona Sul, correspondente a Ipanema e Leblon, começa a ser cada vez mais ocupada. As casas tendem a ser substituídas por edifícios. A especulação imobiliária eleva os preços e Ipanema se torna um dos bairros mais caros do Rio de Janeiro.

Já a orla da Barra da Tijuca só passa a ser ocupada a partir de meados da década de 1960, pela dificuldade de acesso a partir da Zona Sul. Aquela região, até então pouco habitada, tinha uma imagem de natureza intocada e até mesmo de impossível ocupação, graças à falta de infra-estrutura. A intensificação da especulação imobiliária acontece no período do "milagre econômico", a partir da década de 1970, quando ocorreu a expansão da área ocupada pela elite da cidade em direção a São Conrado e Barra da Tijuca. Através da interferência do poder público foi construída a Auto-Estrada Lagoa-Barra, abrindo uma vasta área, ainda com grande parte em estado natural, para atuação do capital imobiliário.

Privilegiada por sua natureza exuberante e pela existência de grandes espaços edificáveis, a Barra da Tijuca exerce forte atração, principalmente sobre as famílias economicamente abastadas que anseiam por melhorar ainda mais sua "qualidade de vida" e também sobre grandes empresas imobiliárias. A indústria imobiliária vende o "morar à beira-mar", mas sem os problemas da Zona Sul, em condomínios com os sugestivos nomes de Novo Leblon ou Nova Ipanema. O resultado desse processo foi o crescimento do número de habitantes, que em 1970 era de 5.779 e passa para 174.353 em 2000; ou seja, uma população 30 vezes maior num período de 30 anos (IBGE, 1970-1980, 1991, 2000).

A Barra da Tijuca era a única possibilidade de expansão da Zona Sul, mas também a opção mais atraente dos chamados "emergentes" das zonas Oeste e Norte da cidade. A convergência dos interesses de localização desses grupos - originalmente pertencentes a regiões do espaço social tão distintos - parece vir, ao longo desses anos, acirrar ainda mais a disputa pela região. A camada oriunda da Zona Sul, com um nível social mais elevado tende a reproduzir comportamentos e valores expressivos de sua origem, enquanto a camada proveniente de outras regiões tende a seguir os passos da primeira em busca de ascensão social. Nesse sentido, parece haver semelhança entre o comportamento dos moradores da Zona Sul e o dos da Barra da Tijuca, nos dias de hoje. 
A criação do mito "Copacabana", assim como "Ipanema" ou "Barra", só é possível em um tipo de sociedade em que exista uma identificação entre local de residência e prestígio social de tal forma acentuada que a simples mudança de bairro possa ser interpretada como ascensão social, mesmo não havendo alterações na ocupação ou na renda das pessoas em pauta (VELHO, 1989, p.89).

Essa sociedade é, para essas pessoas, constituída por estratos que têm como uma de suas definições essenciais a sua distribuição espacial que vai ser fundamental para definir o status dos indivíduos, atribuindo-lhes mais ou menos vantagens ou privilégios que são, basicamente, as oportunidades de acesso a determinados padrões materiais e não-materiais. Os estratos têm limites claros, à medida que se definem espacialmente. Não se confunde um morador de Copacabana com um de Ramos, porque estão identificados socialmente pelo bairro em que moram (VELHO, 1989, p.81).

Com a disputa pelo mesmo espaço entre grupos socioculturais distintos, começa a haver o retorno à Zona Sul da cidade da elite que havia migrado dessa região. Acredita-se que, com esse retorno, passam a predominar os segmentos sociais "emergentes" na região da Barra da Tijuca. Os valores e os códigos constituídos por estes grupos, que detém capital econômico mas carecem de capital cultural, parecem indicar a tentativa de reprodução dos hábitos da elite da Zona Sul.

As condições associadas numa classe particular de condições de existência produzem o habitus, um sistema de disposições duráveis e transferíveis, estruturas que tendem a funcionar como estruturantes; quer dizer, como princípios que geram e organizam práticas e representações passíveis de serem adaptadas objetivamente aos seus resultados, sem pressupor um fim objetivo consciente ou um domínio expresso das operações necessárias para que seja atingido. Objetivamente 'regulador' e 'regulado' sem ser de qualquer forma o produto de obediência a regras, o habitus pode ser orquestrado coletivamente sem ser o produto da ação organizadora de um condutor (BOURDIEU, 1990, p.53).

Este artigo pretende abordar qualitativamente os hábitos de consumo de bens e serviços destinados à elite, em seus vínculos com a dinâmica do espaço urbano. Em se tratando de espaço e consumo, mais especificamente, encontram-se na literatura especializada contribuições científicas que procuram mensurar as demandas com base em informações quantitativas. Entre as principais técnicas de abordagem quantitativa, usualmente utilizadas no estudo de relações de espaço e consumo, destacam-se:

- modelo de localização baseado na Teoria do Lugar Central - desenvolvido por Walter Christaller na década de 1930. Em linhas gerais, expressa o seguinte axioma: o percurso máximo que um consumidor está disposto a percorrer para adquirir um determinado produto deve ser maior do que o raio onde se encontram os clientes capazes de sustentar o estabelecimento comercial;

- Modelo Analógico - técnica não-estatística desenvolvida por William Aplebaum, outro grande estudioso da questão das localizações comerciais, contemporâneo de Christaller. Baseado em um checklist até hoje muito usado pelas cadeias de varejo. Esse modelo consiste em mensurar vendas com base em dados críticos de outras operações análogas;

- a seguir, surgem os modelos gravitacionais fundamentados na física newtoniana, tais como Modelo de Utilidade da Loja (MCI), Axioma de Luce e Modelo de Reilly;

- finalmente, o Modelo Gravitacional de Huff - mais famoso de todos, foi desenvolvido por David Huff, com base nos modelos anteriormente mencionados. De forma resumida, procura estimar o poder de atratividade de uma loja, ou aglomerado de lojas, relacionando a área correspondente a esse espaço (podendo ser medido também através da força da marca ou da riqueza do sortimento de produtos) com a distância da loja em relação a um grupo determinado de consumidores;

- diversos outros modelos também são utilizados para orientar a distribuição espacial de bens e serviços, tais como: Modelo de Locação-Alocação; Polígono de Voronoi (modelo de interação) e Anéis de Thunen. Esse último estabelece um padrão de alocação espacial para a indústria, comércio e residência em forma de anéis, conforme a lógica de valorização do solo no sentido centro/periferia. Mais recentemente, David Huff lançou 
um novo modelo que pode ser trabalhado diretamente acoplado ao software de GIS (Geographic Information System) MapInfo;

- é comum também a utilização do modelo estatístico de regressão, que busca encontrar variáveis independentes, capazes de explicar o comportamento de uma determinada variável dependente.

Tais modelos apresentam limitações, assim como qualquer tipo de modelo ou opção metodológica; exceto, é claro, quando a escolha depende exclusivamente do esforço de deslocamento ou do preço. É o caso dos produtos de baixo valor simbólico agregado, como, por exemplo, um quilo de arroz ou um remédio. Em tal circunstância, é razoável trabalhar com modelos estatísticos e não-estatísticos vigentes. Mas, com a crescente sofisticação dos produtos e das formas de consumo, torna-se também maior a importância simbólica destes. Assim, a compreensão dessas questões passa a requerer novas abordagens que privilegiem aspectos qualitativos do comportamento do consumidor.

O entendimento é o de que para um estudo consistente relacionado a espaço e consumo, é necessário o desenvolvimento de conhecimentos concebidos de forma interdisciplinar. Portanto, a antropologia social e os estudos de sociologia urbana oferecem um arcabouço teórico poderoso para uma profunda compreensão do consumo de bens e serviços de alto valor simbólico agregado. Essas abordagens foram utilizadas com sucesso na dissertação de mestrado deste autor.

\section{As elites e a disputa pelo espaço social}

Para identificar os grupos que compõem a elite, são consideradas as formas de capital que melhor garantem e sustentam os seus valores e estilo de vida. Até o momento, tem sido utilizada a expressão "elite" como sendo o melhor conceito para indicar, numa abordagem ainda pouco complexa, a camada social detentora de diversos capitais. Considerando, a partir de agora, a grande complexidade da produção simbólica da sociedade atual, optou-se por se definir a camada que ocupa a posição hegemônica na sociedade de "grupo detentor do capital simbólico". Esse é o termo que parece melhor representar esse segmento da elite. Tal conceito não se baseia unicamente no poder econômico, mas fundamentalmente na reunião de diversos capitais, dos quais o cultural ocupa uma posição especial. É da complexa composição desses capitais que emerge a noção de capital simbólico. Todos os grupos sociais possuem seus próprios valores simbólicos. Isso não significa que detenham a capacidade de deliberar livremente sobre eles. As representações construídas pelo grupo que detém a "deliberação" do valor simbólico de grande parte dos objetos, pessoas, idéias e lugares orientam a forma de agir e pensar da sociedade. O controle do capital simbólico pressupõe também, de alguma forma, o atendimento de expectativas coletivas, pois só existe na medida em que seu valor é socialmente reconhecido pelos outros.

Portanto, entende-se como "grupo detentor do capital simbólico" aquele que é reconhecido pela sociedade como detentor do mais elevado prestígio social, ou seja, aquele que delibera a respeito dos valores simbólicos de grande parte dos objetos, pessoas, idéias e lugares, não só dentro do seu grupo como também, de forma direta ou indireta, para toda a sociedade. Não se trata de um grupo claramente delimitado, mas sim de um segmento dotado de uma configuração de capital semelhante ou equivalente que, mesmo sem ter consciência, é percebido pela sociedade como uma unidade. Entre os diversos capitais envolvidos, o capital cultural parece ser aquele em que esse grupo fundamenta a sua diferenciação social. A estética possui uma importância decisiva na manifestação do capital cultural, através do "bom gosto" no vestir, na forma de decorar os ambientes, no apreço pela arte e pelo belo. Outra importante forma de expressão da estética é aquela através dos códigos intrínsecos na expressão corporal (gestos, olhares, tons de voz etc.). Portanto, o capital cultural e suas formas de manifestação sustentam a hegemonia exercida sobre todas as outras formas de expressão do poder.

O grupo detentor do capital simbólico é composto fundamentalmente por famílias que controlam organizações empresariais há algumas gerações, famílias tradicionais da sociedade carioca, intelectuais e profissionais liberais com excepcional nível de formação e alto prestígio social. Neste caso, a grande concentração desse grupo parece estar essencialmente na Zona Sul. 
Ter um grande acúmulo de capital econômico não parece ser uma condição para que indivíduos sejam aceitos por membros desse grupo. É possível observar a inserção nesse grupo de indivíduos que não detém necessariamente grande acúmulo de capital econômico, mas que tiveram acesso a uma excelente educação, serviços e lugares que acabaram promovendo naturalmente a aproximação. Portanto, membros de famílias de classe média alta que tiveram acesso a uma formação de alto nível (principalmente com inclinação européia) e que possuem hábitos de vida que se aproximam e se encaixam nas "exigências" do grupo detentor do capital simbólico, são considerados como parte deles. Da mesma forma, membros de famílias tradicionais que na última geração perderam o acesso à formação, convívio e identidade não são considerados como parte deles.

Já a elite da Barra da Tijuca parece ser representada fundamentalmente por uma classe popular e média ascendente à classe alta, formada por executivos, por pequenos e médios empresários do setor formal e informal, atletas de destaque, artistas de televisão, dirigentes esportivos etc. É importante a segmentação dessa camada em grupos, devido a sua heterogeneidade em termos de trajetórias sociais e valores. Trata-se, a princípio, de grupos que têm em comum, além da escolha da localização para sua reprodução social, um habitus fortemente concentrado no capital econômico. Portanto, neste artigo, esse segmento da elite foi denominado "grupos dos economicamente emergentes". Ao longo da pesquisa, esses grupos serão claramente segmentados de acordo com os novos conhecimentos adquiridos.

Nesse sentido, é fundamental esclarecer que os membros dos grupos referidos neste estudo são independentes e estabilizados em suas trajetórias profissionais. Não são considerados os membros jovens dependentes e os adolescentes, a não ser de forma agregada aos seus pais. Acredita-se que esse segmentos em fase de maturação, onde os valores estão ainda sujeitos a grandes transformações e que são sensíveis a atitudes contestadoras em relação à sociedade em geral, provocariam distorções na avaliação de uma tendência de comportamento. Nesse aspecto, é levado em conta uma delimitação importante para futuras pesquisas que aprofundem a conhecimento sobre o tema.

Além da suposição de que os grupos economicamente emergentes desejam seguir uma trajetória social semelhante ao grupo detentor do capital simbólico, é possível observar que desenvolveram, tal como este, valores expressos através de seu habitus que formam e fortificam a demanda por bens, serviços e lugares que atendam às suas necessidades e desejos. Logo, em função da posição social que ocupam e dos hábitos de consumo a que estão associados acabam, por sua vez, sendo referência para outros grupos sociais que estão abaixo na hierarquia social. Dessa forma, podemos supor uma sociedade encadeada e hierarquizada, onde um determinado grupo possui como referência um outro considerado superior na escala social e que possua um conjunto de valores mais próximo ao dele. Enquanto isso, no ápice desse espaço social, está o grupo detentor do capital simbólico.

Na figura 1 pode-se observar um exercício reflexivo sobre o espaço social com base na idéia de hierarquia aqui desenvolvida. 
Figura 1

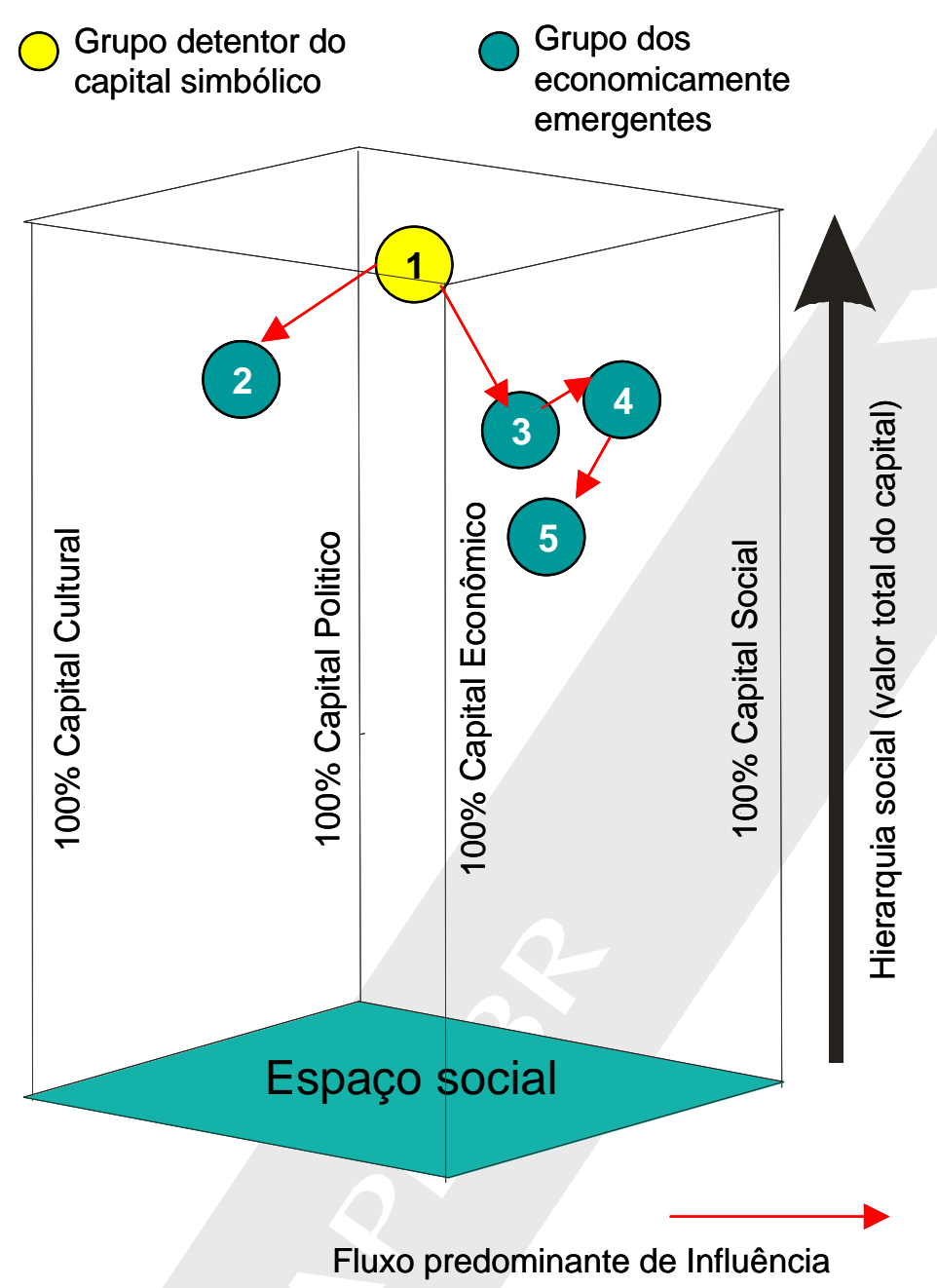

Fonte: desenvolvido por Luiz Henrique Lemos.

Foram plotados apenas os grupos estudados neste artigo. O grupo 1 representa o detentor do capital simbólico. Sugere-se o grupo 2 como sendo o grupo dos artistas e executivos da mídia. O grupo 3 representa os executivos, os pequenos e médios empresários da economia formal e os funcionários públicos com alta graduação. $\mathrm{O}$ grupo 4 é o dos dirigentes esportivos, e o grupo 5 é o dos jogadores de futebol e dos pequenos e médios empresários da economia informal.

Além do grupo 1 ser o detentor do capital simbólico, pode ser o grupo de referência do 2 e do 3 , assim como o 4 pode ser o do 5. Portanto, o grupo detentor do capital simbólico não é necessariamente o grupo de referência direto para todos os demais grupos do espaço social.

Acredita-se que, na afirmação da distinção, o grupo detentor do capital simbólico passa a valorizar cada vez mais o capital cultural como parte fundamental do seu habitus. Dessa forma, esse grupo se mantém protegido e diferenciado diante dos que não atendam às exigências culturais e sociais por ele estabelecidas.

Ser detentor de um prestigioso sobrenome, saber apreciar um bom vinho, morar por um bom tempo em Paris ou ter a oportunidade de conhecer profundamente grande parte da Europa, saber apreciar uma bela obra de arte, freqüentar clubes - tais como Jockey Club, Hípica, Caiçaras, Paissandu ou Country Club -, ou mesmo manter os filhos estudando em escolas suíças ou inglesas; enfim, vivenciar todos ou alguns desses artefatos simbólicos parecem credenciar os indivíduos a fazerem parte dessa elite, unida por códigos traduzidos em gostos, acessos e interesses comuns. Tais códigos demandam um grande esforço para serem conquistados e acabam sendo 
controlados objetivamente pelo grupo que concentra o maior valor total de capital. Já que o poder econômico não garante o acesso a essa camada da elite, apela-se para o que está ao alcance, pelo menos daqueles que detém capital econômico. Nesse contexto, há luta pelo acesso a alguns símbolos associados à camada detentora de capital simbólico e que, mais democraticamente ofertados, dependem exclusivamente do poder econômico, tais como local de residência, roupas, carros, viagens ao exterior, academias de ginástica "da moda", restaurantes sofisticados e, finalmente, freqüência aos locais de consumo desses bens e serviços posicionais.

Para alguns segmentos da classe dominante, a imagem constitui um instrumento de poder e, também, um excelente recurso, adicionado em associação com numerosas outras expressões culturais, dependentes do pleno domínio da fala e da escrita e, também, do controle da sua divulgação. Nessa relação privilegiada com a imagem, estão incluídas, é claro, oportunidades de elaboração da subjetividade e formas exclusivas de sociabilidade e promoção de interesses (RIBEIRO, 2001, p.54).

Podemos dizer que quanto menor for o esforço e os recursos necessários para a adoção de um novo hábito, mais rapidamente este será desconsiderado pelo segmento que concentra o maior valor total de capital. Uma boate destinada inicialmente à elite, nos primeiros meses se mantém "povoada" por seus componentes. Após alguns meses, transforma-se em função da adesão de "novos" usuários e, com isso, é imediatamente abandonada pelos seus primeiros freqüentadores. A boate Hipopotamus teve uma duração excepcional justamente porque só podia ser freqüentada por "associados". Tal artifício manteve durante muitos anos esse estabelecimento como símbolo de sofisticação das casas noturnas cariocas. É em razão do desejo dos indivíduos de assemelhar-se àqueles que são considerados superiores, aqueles que brilham pelo prestígio e pela posição, que os decretos da moda conseguem propagar-se (LIPOVETSKY, 2001:40).

\section{Considerações finais e perspectivas para pesquisas futuras}

Neste artigo, o entendimento é o de que a formação do habitus dos diversos grupos sociais é determinada pelas diferentes trajetórias sociais dos indivíduos e pela configuração dos diversos capitais. Através desses elementos é possível compreender a lógica das percepções, as escolhas e utilizações das localizações e de produtos de consumo. Essa lógica torna-se ainda mais evidente quando são comparados grupos que disputam entre si uma posição de poder no espaço social, motivados por objetivos diferentes. Enquanto os economicamente emergentes buscam uma trajetória de ascensão social semelhante ao grupo detentor do capital simbólico, este deseja se distinguir daquele. Essa disputa parece influenciar fortemente na formação de seus habitus. Enquanto os economicamente emergentes tende a fundamentar seu habitus no capital econômico, o grupo detentor do capital simbólico parece fundamentar seu habitus no cultural, percebido como "mais distintivo". Tais valores teriam sua mais ampla expressão nos hábitos de consumo, no gosto (estética) e na apropriação seletiva de lugares.

São muitas as evidências empíricas das diferentes formas de consumo, de gosto e de apropriação e utilização de lugares entre a Zona Sul e a Barra da Tijuca. Essas distinções podem ser parcialmente explicadas por diferentes circunstâncias sociais objetivas, dentre elas a escalada da violência urbana e os parcos investimentos em transporte público, que estimularam a migração de parte das camadas sociais mais abastadas das diversas regiões da cidade para os condomínios fechados e os confortáveis shopping centers. Mas é observável, também, que esse movimento veio acompanhado de uma considerável imbricação de grupos sociais das mais diversas origens. Isso produziu uma forte reação de distinção do grupo detentor do capital simbólico que, em parte havia migrado para a Barra, mas que permanecia com seus vínculos socioculturais fortemente sedimentados na Zona Sul. Parte desse grupo acaba retornando para a Zona Sul, principalmente, como forma de reafirmação de sua identidade. Esse processo de disputa e ocupação de lugares parece intensificar o sentimento de identidade e diferença entre esses grupos. Nesse sentido, o capital econômico deixa de ser um fator de diferenciação. No bojo desse movimento, define-se um conjunto de percepções e estigmas que se constituem muitas vezes através da afirmação da identidade, pela negação daqueles elementos simbólicos que parecem constituir a identidade do outro. Ao luxo estilo norte-americano adotado pelos grupos emergentes da Barra, a elite da Zona Sul opõe a elegância em moldes europeus. Contra a ostentação do novo, opõe a valorização do histórico. Em oposição ao novo modelo "ultraplanejado", "sem charme e sem esquinas" da Barra da Tijuca, a elite da Zona Sul defende a 
valorização do Centro, da Lapa e de Santa Teresa. Dessa forma, reforçam-se as diferenças, já não mais pela força do capital econômico, mas, fundamentalmente, através do capital cultural em seu vínculo complexo com a preservação do poder.

Para futuras investigações, sugere-se a confirmação das suposições apresentadas neste estudo, bem como o aprofundamento da análise sobre o impacto dessas disputas sociais no consumo, na dinâmica da apropriação do espaço urbano e, consequientemente, no mercado imobiliário. Essas questões não têm sido exploradas com a devida profundidade.

O entendimento é o de que pesquisas sobre esse tema tenham grande importância para organizações públicas e privadas responsáveis pela distribuição de bens e serviços ao consumidor, possibilitando um maior embasamento na tomada de decisões. À medida que se tem conhecimento de que os grupos se apropriam de determinados lugares, munidos de elementos culturais associados à sua posição social, a expectativa é a de que reproduzam a sua cultura nesses lugares. Por sua vez, a cultura se manifesta fortemente através de hábitos de consumo. A identificação e o cruzamento dessas categorias de análise propiciam avaliar onde os investimentos se revelam mais adequados. Os modelos matemáticos em geral e as tecnologias de informação são ferramentas que podem e devem ser utilizadas em complemento a abordagens qualitativas tal como a que está sendo proposta neste artigo. 


\section{Referências bibliográficas}

ABREU, M. A. Evolução urbana do Rio de Janeiro. Rio de Janeiro: Iplanrio, 1997.

ALASUUTARI, P. Researching culture: qualitative method and cultural studies. London: SAGE Publications Inc., 1995.

BOURDIEU, P. The logic of practice. Stanford: Stanford University Press, 1990.

Razões práticas. 3.ed. Campinas: Papirus Editora, 2001.

CRAIG, C. S.; GHOSH, A.; MCLAFFERTY, S. M odels of the retail location process. USA: A review. Jornal of Retailing, v.60 n. 1, 1984.

FRAIHA, S.; LOBO, T.; RIBAS, M. Bairros do Rio: Leme e Copacabana. Rio de janeiro: Editora Fraiha, 2000.

IBGE. Censos demográficos 1970-80 (arquivos de microdados).

IBGE - Censo demográfico 1991.

IBGE - Censo demográfico 2000.

LAGO, L. C. Desigualdades e segregação na metrópole: o Rio de Janeiro em tempo de crise. Rio de Janeiro: Editora Revan, 2000.

LIPOVESTKY, G. 0 império do efêmero. São Paulo: Companhia das Letras, 2001.

MALHOTRA, N. K. Pesquisa de marketing: uma orientação aplicada. Porto Alegre: Bookman, 2001.

MATTOS, C. L. G. A abordagem etnográfica na investigação científica. Revista Espaço, n.16, jun./dez. 2001. Disponível em: $<$ <ttp://www.ines.org.br/paginas.htm>. Acesso em: 25-3-2003.

MELLO, N. D. C. Diferenciação residencial e classes sociais na cidade do Rio de Janeiro. In: ENCONTRO NACIONAL DOS GEÓGRAFOS, 4., Rio de janeiro, 1980 Anais... Rio de Janeiro, 1980.

MORSE, J. M. Designing funded qualitative research. In: DENZIN, N. K., LINCOLN, Y S. (Ed.). Handbook of qualitative research. London: Sage, 1994.

OLIVEIRA, F. 0 estado e o urbano. Espaço \& Debates, São Paulo, n.6, p.36-54, 1982.

OLIVEN, R. G. Antropologia de grupos urbanos. Petrópolis: Editora Vozes, 1996.

RIBEIRO, A. C. T. A atualização da cidade: imagem, violência e classes sociais. Cidade- galeria: arte e os espaços urbanos. In: ENCONTRO DO PROGRAM A DE PÓS-GRADUAÇÃO EM ARTES VISUAIS, 8., 2001, Rio de Janeiro: UFRJ, 2001.

RICHARDSON, R. J. Pesquisa social: métodos e técnicas. São Paulo: Atlas, 1999.

SANTOS, M. Território e sociedade - uma entrevista com Milton Santos. São Paulo: Editora Fundação Perseu Abramo, 2000.

Por uma outra globalização: do pensamento único a consciência universal. Rio de Janeiro: Record, 2002.

TRIVIÑOS, A. N. S. Introdução à pesquisa em ciências sociais. São Paulo: Atlas, 1987.

VELHO, G. A utopia urbana. Rio de Janeiro: Jorge Zahar, 1989.

WOODWARD, H.; YNHALL, S.; SILVA, T. T. (Org). Identidade e diferença: a perspectiva dos estudos culturais. Petrópolis: Editora Vozes, 2000. 